\title{
APONTAMENTOS PARA A HISTÓRIA DO SIMBOLISMO NO BRASIL
}

\author{
JOSE ADERALDO CASTELLO. \\ Assistente da Cadeira de Literatura \\ Brasileira da Fac. Filosofia, Ciências e \\ Letras.
}

Dos críticos de fins do século XIX, Araripe Júnior foi o que nos deu informações mais completas a respeito da introdução do simbolismo no Brasil. Justifica-se, porque uma das características dêste ilustre crítico, hoje tão injustamente esquecido, foi a particular simpatia que sempre procurou dispensar a tôdas as correntes de inovação literária.

Em 1893, Araripe Júnior escreveu para a revista $A$ Semana, então em sua segunda fase dirigida por Valentim Magalhães e Max Fleiuss, uma série de artigos, três anos mais tarde publicada em volume sob o título Movimento de 1893 (1). Entre êsses artigos de crítica, alguns há sôbre o movimento simbolista, de apreciável valor histórico e crítico, pois noticiam a sua introdução no Brasil; e igualmente nos dão uma síntese dos fundamentos estéticos do simbolismo, produto de impressões pessoais, mas tão bem apreendidas que coincidem perfeitamente com as opiniões mais acatadas da crítica posterior. Principiam ressaltando que o acontecimento de maior relêvo da vida literária do ano anterior, havia sido "a tentativa de adaptação do decadismo à poesia brasileira", sob a responsabilidade de Cruz e Souza.

Contudo, antes da tentativa definitiva de Cruz e Souza, houve outras também no sentido de divulgar e adaptar as idéias simbolistas. $\mathbf{E}$ foi

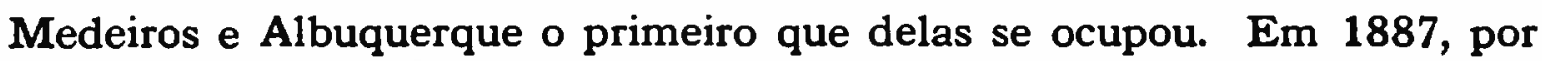
intermédio de um amigo relacionado em Paris com o grupo de Mallarmé, conseguiu reunir as melhores produções dêste, de Verlaine, René Ghil, St. Merril, João Moréas, bem como revistas em que Vieillé Griffin, Paul Adam, Charles Viguier e outros difundiam as novas idéias e combatiam o realismo. Sugestionado pelas recentes atitudes estéticas, $\mathrm{Me}$ deiros e Albuquerque logo escreveu e publicou as Canções da decadência em que, como observou Araripe Júnior, "aproveitando muito pouco dos cânones revelados pelos mestres da escola, apenas procurou tirar alguns efeitos da instrumentação inventada pelo autor do Tratado do Verbo e 
do policromatismo estilístico deduzido das letras do alfabeto" (2). Depois desta realização, Medeiros e Albuquerque entregou-se a outras atividades, abandonando as pretensões simbolistas ou decadistas.

$\mathrm{E}$ foi Araripe Júnior quem realmente aproveitou o material de que dispunha Medeiros e Albuquerque. Naquele mesmo ano de 1887, de posse dos livros e revistas do irreverente autor de Quando eu era vivo, Araripe Júnior passou a estudar as novas idéias, então bastante combatidas. Elas o impressionaram, diz, e foi levado "a concluir que o decadismo ou simbolismo em Paris, constituía o sintoma ou a repercussão de um fenômeno misterioso, algures agitado em virtude de causas muito poderosas" (3). Não satisfeito com os esclarecimentos da crítica, preferiu êle mesmo apreciar o material simbolista que tinha em mãos. Reconheceu que o decadismo era "uma nova forma de chauvinismo parisiense, produzido pelo movimento geral que ia agitando a Europa, ação esta que a maior parte dos decadistas e simbolistas desconhecia ou rejeitava. "Convencido disto" - continuava - "escrevi então, em 1888 no Novidades alguns artigos intercorrentes à crítica de um livro em voga, nos quais procurei demonstrar que a nova escola, sendo històricamente uma transformação do parnasianismo, em cuja alma se injetara um raio dêsse espírito que no princípio do século dera como produtos a poética religiosa dos Saint-Simon, dos Enfantin, dos Pierre Leroux, tomava a forma simbólica do orfismo de Mallarmé." Observou que o grupo de inovadores simbolistas oscilava entre dois polos: de um lado, as sutilezas gramaticais, com os caprichosos truncamentos de sintaxe, visando determinados efeitos; e, "de outro lado, o horror às literaturas militantes de estranhos países e a infernal aspiração de criar aptidões novas ao espírito, nova afirmação aos nervos, e de exprimir o inexprimível, tudo isto, porém, mais ou menos subordinado a um ponto de vista galo-latino" (4). Ainda mais, encontrou nos diveásos representantes das novas tendências ponto de contato com a poesia de Lamartine, de Victor Hugo, de Baudelaire, e até de Ronsard e Villon.

Afirmou que, de qualquer forma, o decadismo constituía um simples acidente literário, prenúncio de fenômenos mais elevados; e, do ponto de vista social e político, parecia-lhe um movimento continental. Concentrara-se em Paris todo o exotismo europeu, traduzido pelo tolstoísmo, vogueísmo, ibsenismo, ocultismo, orientalismo, japonismo, americanismo. Houve nêcessidade de defesa dos nativistas franceses; criou-se o decadismo. 
Firmaram-no, segundo Araripe Júnior, en três pontos principais: erudição românica, medievalismo e filologia comparada. Mas, nem todos conheciam história e filologia; e os que apresentavam essa insuficiência, declararam-se "simples" e passaram a copiar os vilancetes, as "aubades", os "Leit Motiv" dos menestréis.

O movimento simbolista, com berço na França, espalhou-se pela Europa. Para o Brasil, não veio diretamente de Paris; escalou primeiramente em Portugal onde, para Araripe Júnior, tudo se deforma. engrossa, toma feição ridícula. Essa informação do crítico citado é parcialmente exata; já vimos coino, diretamente vindas de Paris, as idéias simbolistas principiaram a ser divulgadas no Brasil, fato na sua maior parte devido ao próprio Araripe Júnior, a Medeiros e Albuquerque e também ao dr. Gama Rosa, a quem o primeiro transmitiu o material de que dispôs, dando-lhe margem a que escrevesse um trabalho sôbre - assunto, publicado na "Tribuna Liberal" na mesma época dos de Araripe Júnior (5). Só o acentuado anti-lusismo dêste crítico que sempre procurou oportunidade para ridicularizar o velho Portugal - e vimos em que têrmos se referiu à inteligência portuguêsa - pôde parcialmente justificar a informação que nos prestou. Mas, como dissemas, em parte ela é verdadeira.

As primeiras atitudes simbolistas pròpriamente ditas, de execução dos novos processos, datam entre nós de 1890-1891, quando se formou em tôrno da Fôlha Pcpular, então secretariada por Emiliano Perneta, um grupo de inovadores que adotaram como insígnia um fauno; a êle, pertenciam Bernardino Lopes, Emiliano Perneta, Oscar Rosas e Cruz e Souza. O primeiro havia publicado Cromos, livro de inspiração bucólica, passando dêsse motivo para os de castelos e de duquesas ideais; já apresentava, na observação de Araripe Júnior, tiques decádistas antes da divulgação do simbolismo entre nós, pois à sua natureza e temperamento repugnava a atitude parnasiana. $E$ B. Lopes influenciou os demais, levando-os a cultivar inicialmente um tipo de poesia bucólica (6). Oscar Rosas, êste se dizia simbolista, sem realmente o ser, preso como estava às tendências naturalistas. $\mathbf{A}$ atitude definitiva coube, porém, a Cruz e Souza que, "no intuito claro, manifesto, de acompanhar o nefelibatismo português" (7), publicou Missal e Broquéis, ambos em 1893.

Cruz e Souza tornou-se chefe do movimento entre nós; logo mais foi seguido de outros novos, como Saturnino Meireles, Félix Pacheco, Nestor Victor, Gonçalo Jácome, Colatino Barroso, Wenceslau 
de Queiroz (8), Carlos Dias Fernandes (9) e outros que, se discípulos de Cruz e Soúza, não o imitaram, firmados numa atitude sem dúvida própria do simbolismo que se caracterizou pela expressão acentuadamente individualista de seus adeptos.

Nestor Victor aos poucos também se tornou figura central do movimento, o principal responsável pela sua interpretação. E' curioso o que diz a respeito das situações iniciais dos simbolistas brasileiros: "Nós, sobretudo Cruz e Souza, eu, Emiliano Perneta, Gonzaga Duque, Colatino Barroso, trazíamos o ar mais desesperado, por antecipação, de quem não confia na atmosfera em tôrno. O sentimento inicial nosso era o de que vínhamos declamar, lembrando aquêle grande clássico orador português, para os peixes." (10)

Criava-se assim a atmosfera simbolista com a formação de grupos que foram combatidos e também combateram, tomando uma posição essencialmente dissente em face da forma literária consagrada, estendendo sua ação até as artes plásticas. Carlos $\mathrm{D}$. Fernandes refere-se à dissidência que, já por volta de 1887, houve entre os alunos da Escola de Belas Artes do Ric de Janeiro, os quais se dividiram em dois grupos: "um, fiel à tradição didática dos professôres; outro infenso aos métodos, que se ali praticavam, jungindo muito à cultura clássica as aspirações estéticas dos insurretos." Décio Vilares chefiava os dissidentes; e êle, Carlos Fernandes e Tibúrcio de Freitas formavam o grupo mais achegado a Cruz e Souza, a quem muito admiravam como artista e como homem (11). Dois outros nomes merecedores de destaque, que pertenceram ao grupo de pintores revolucionários, foram Maurício Jubim e Gonzaga Duque, o último então preocupado exclusivamente com pintura e crítica de artes plásticas.

Eles, os chamados insubmissos, relacionaram-se estreitamente com - grupo simbolista de Mário Pederneiras, Lima Campos e também Gonzaga Duque, tributando todos, sem qualquer restrição, verdadeiro culto a Cruz e Souza. Lima Campos, em depoimento a respeito de seu grupo (12), refere-se inicialmente a Mário Pederneiras, o chamado "Poeta da Cidade", filiado ao simbolismo desde suas primeiras produções literárias. Para êle e demais companheiros, por êsse tempo, fins do século XIX, Paris era, como Verlaine, Moréas, Barrès, Samain e outros, o centro para onde convergiam tôdas as atenções. Imitando-os, fazendo igualmente o que já haviam feito os simbolistas de Lisboa, chefiados por Eugênio de Castro, os do Rio de Janeiro também instituíram o seu François I, que era o Cabaré Pelotense, já preferido e fre-n 
qüentado pelos pintores insubmissos que mencionàmos. Sem qualquer vislumbre de modéstia, o grupo simbolista do Cabaré Pelotense julgat va-se os "Magnificentes da Palavra Escrita", subtitulando-se "Romeiros da Estrada de San-Tiago". Eram ao todo uns vinte e procuravam oportunidades para se exibirem, dirigindo-se a jornais, revistas, editôres, palcos. Pouco tempo se mantiveram coesos; dispersaram quase todos, três ou quatro anos depois de reunidos, permanecendo solidários apenas Gonzaga Duque, Mário Pederneiras e Lima Campos.

Fundaram algumas revistas de efêmera duração, como por exemplo a Rio-revista, de 1895, e de pouco depois o Mercúrio, ilustrado por Raul Pederneiras, Julião Machado e Benedito Calixto. E, mantendo-se solidários, conforme dissemos, Mário Pederneiras, Gonzaga Duque e $\mathrm{Li}$ ma Campos fundaram a revista Font-fon, anos mais tarde, em 1908, revista que nos seus primeiros anos apresenta apreciável material literário e documental. E' bastante lembrar que também contou com a cooperação e colaboração de Olegário Mariano, Felipe de Oliveira, Hermes Fontes, Âlvaro Moreira.

O grupo que se dispersou, compunha-se de nomes dignos de menção: B. Lopes, Emiliano Perneta, Emílio de Menezes e Luiz Delfino (êstes dois não foram pròpriamente simbolistas), Félix Bocaiúva, Virgílio Várzea, Araújo Figueiredo, Azevedo Cruz, Alphonsus de Guimaraens, Oscar Rosas. Foi o último que, juntamente com Cruz e Souza, pretendeu ou pretenderam o separatismo nas letras: literatura do sul e literatura do norte, idéia que, na verdade, não vinha dos simbolistas, mas sim do romancista Franklin Távora. De qualquer forma, aquêles simbolistas não tiveram o apoio dos demais, e o que pretenderam não passou de uma simples blague feita aos meios literários nortistas, como já notou Lima Campas.

Mencionamos que os poetas simbolistas distribuídos nos dois grupos indicados (grupos que na realidade constituíam um único, se levarmos em conta o ideal comum a ambos), fundaram algumas revistas que muito bem os representam. Ressaltamos a Rio-Revista, a Vera-Cruz; e por fim a Rosa-Cruz, fundada já em princípios do século atual pelo terceiro e último grupo simbolista de que temos notícia. Merecem particular destaque, porque foram feitas rigorosamente de acôrdo com o ideal, processos e método simbolistas.

O principal fundador da Rio-Revista, em 1895, foi Gonzaga Duque. Na Revista Terra de Sol, há tempos fundada e dirigida por Tasso da Silveira, encontram-se algumas cartas de Gonzaga Duque, di- 
rigidas a Emiliano Perneta, em duas das quais se refere à Rio-Revista. dando-nos êle mesmo uma idéia do que ela era e do que pretendiam. Na primeira, datada de 9. 5. 1895, escreve: "Com esta remeto-te o $10^{\circ}$ número da Ria-Revista, que conseguimos fundar. Aí verás a nossa gente, tôda a bande joyeuse da boemia dissidente, lutando pelo Grande Ideal. Falta o teu nome. O soneto que me mandaste para uma revista que pretendíamos publicar ficou, com todos os originais reunidos nas garras ferozes do idiota que se propunha a editá-lo; e, como eu não desejava importunar-te com pedidos de originais para revistas que não apareciam, protestei não convidar-te para a nossa confraria enquanto os ventos benéficos da realidade não enfunassem os panos da galera d'ouro" (13).

Na segunda carta datada de agôsto do mesmo ano, trata novamente daquela revista: "Manda-me também os teus novos versos, temos a "Rio-Revista" para publicá-los, para ter a honra, o orgulho de os compor em tipo elzevir, e os imprimir em setinoso papel branco como os linhos claros ao luar de Junho" (14).

Mas, a Rio-Revista, como as demais revistas simbolistas, foi de efêmera duração, por causa sobretudo das dificuldades financeiras e das exigências relativas à feição material e à colaboração literária das mesmas, por parte de seus dirigentes. Os trechos de cartas transcritos já nos sugerem isto mesmo. $\mathbf{E}$ vimos como em vão tentaram fundar revistas que não passaram de simples projetos.

A propósito da Vera-Cruz, lembramos as preciosas informações de A. Austregésilo. Principiou a participar dos novos literários em 1896, ao lado de figuras já experimentadas, como Cruz e Souza, Gonzaga Duque, Lima Campos e Mário Pederneiras, e de outros ainda jovens, como Nestor Victor, Oliveira Gomes, Gustavo Santiago, Cardoso Junior, Neto Machado, Luiz Edmundo. Nesta época fundaram a revista Vera-Cruz e instituíram o grupo de "os novos". Obedeciam a um decálogo simbolista que mandaram imprimir em vermelho e negro; defendiam a arte simbolista ou decadista ou nefelibata; e, se foram combatidos, também guerrearam bastante. "Ninguém medianamente sensato - escreve Austregésilo - nos tomava a sério, mas publicávamos livros, revistas, escrevíamos em jornais, reuníamo-nos em tertúlias e tínhamos a bandeira escandalosa de guerra para derrubar os velhos parnasianos, românticos e realistas" (15).

Devotavam admiração a Mallarmé, Moréas, Verlaine, Rimbaud, Eugênio de Castro, Antônio Nobre, João Barreira. Viviam cheios de ilu- 
sões e cultivavam a "tortura literária, a dor artificial, o sofrimento imaginário e o pessimismo mórbido", contaminados como estavam pelo nefelibatismo. Reuniam-se diàriamente nos cafés do Rio de Janeiro ou na Rua do Ouvidor, para discutirem valores, nomes estrangeiros e nacionais já consagrados, usando e abusando da expressão medíocre; sentiam-se argulhosos e ao mesmo tempo insatisfeitos; e para êles "não havia grande brasileiras: tudo, rasteiro e trivial."

Não resta dúvida que o grupo fundador da Vera-Cruz teve uma atitude bem próxima da dos modernistas que fizeram a Semana de Arte Moderna, em 1922, no Teatro Municipal de São Paulo. E também a mesma atitude negativista, insubmíssa e revolucionária do grupo de "os novos", teve o terceiro e, como dissemos, talvez último grupo simbolista.

Surgiu no Rio de Janeiro por volta de 1901 e teve como propósito principal reavivar e homenagear a memória de Cruz e Souza. Fundaram para tanto a revista Rosa-Cruz; aparecida em Junho, manteve-se até Setembro daquele ano, tendo atingido o quarto número (impressa na Tip. do Instituto Profisional); ressurgiu mais tarde, de junho a agôsto de 1904, quando foram publicados mais três números (impressa na Tip. Leuzinger).

O grupo da Rosa-Cruz foi chefiado e inspirado por Saturnino Meireles. Conforme Tavares Bastos, eram os seguintes os que formavam ao lado do hoje tão esquecido autor de Intuições e Astros Martos: Carlos Dias Fernandes, Gonçalo Jácome, Pereira da Silva, Castro Menezes, Paulo Araújo, Tibúrcio de Freitas, Alphonsus de Guimaraens, Maurício Jubim, Rocha Pombo, Félix Pacheco; como simples colaboradores da revista, na primeira fase, contam-se: Luiz Delfino, Cabral de Alencar, Rafaelina de Barros, João Andréia, Colatino Barroso, Carlos Góis, Archangelus de Guimaraens, Miguel Melo e Amadeu Amaral; na segunda fase: Flávio da Silveira, Mário Tibúrcio Gomes Carneiro, H. Malaguti, Bernardes Sobrinho e Roberto Gomes (16). Do grupo pròpriamente dito, os nomes de quase todos os componentes já foram mencionados anteriormente; êle não passa, portanto, de uma sobrevivência dos anteriores.

A Rosa-Cruz apresentou um programa intransigente de guerra aos medalhões, contra a burguesia endinheirada; não admitia anúncios e exprimia verdadeiro ódio ao que os simbolistas chamavam - profundum vulgus. 
Souza Bandeira (17) também menciona a Rosa-Cruz como tendo sido uma revista essencialmente artística, dedicada ùnicamente à arte. Seu principal mantenedor foi Saturnino Meireles, auxiliado pelos outros componentes do grupo, que contribuíam com o auxílio mensal de cinqüenta mil réis tirados dos reduzidos ordenados de repórteres e das escassas mesadas de estudantes. Não admitiam anúncios nem sequer disfarçados em versos, como haviam feito em outras revistas. Sem dúvida eram verdadeiramente idealistas, pelo menos o foi êste admirável Saturnino Meireles, falecido na flor dos anos.

Êle, Saturnino Meireles, tudo fêz, para manter a publicação, dirigindo-se insistentemente a seus colaboradores, já para reclamar a contribuição monetária, já para solicitar matéria literária. Em cartas a Tavares Bastos, fala de sua verdadeira luta para manter a revista, ao mesmo tempo que nos dá elementos, para avaliarmos a grandeza de seu ideal. Alguns trechos merecem destaque, em testemunho de uma geração: "Continuo exilado entre as paredes de meu quarto, tendo sòmente a consoladora companhia de Maeterlinck, Emerson, Carlyle, Novalis, Hello, Swendenberg, Platão, Spinosa, Pascal e tantos outros que das minhas estantes me ensinam a ter a sábia resignação de tudo aceitar com um sorriso nos lábios. E por isso eu encontro sempre uma desculpa para todos vocês que me não procuram. Mas agora precisava de ti um conselho: que hei de fazer para sair o $3 .^{\circ}$ número da Rasa-Cruz, se tu mesmo e todos os demais companheiros não me vêm animar com a sua presença, com o produto do seu espírito e com os meios pecuniários necessários? Manda-me um trabalho teu, a contribuição que prometeste e vem até cá, para não assistirmos aos funerais de tão bela revista."

E em outro trecho de uma segunda carta: "Manda-me o teu trabalho e o mais que prometeste; mas caso só tenhas o trabalho, manda só o trabalho. Não compreendes o quanto luto para dar essa revista Além de falta de recursos, falta o auxílio espiritual." E em terceiro trecho de carta transcrito por Tavares Bastos, Saturnino Meireles mostrase cada vez mais abatido, quase vencido pela doença que o consumia e, já desanimado, oferece para qualquer um a direção da revista (18).

A Rosa-Cruz e o seu grupo procuravam elevar Cruz e Souza ao ma1s alto grau da consagração. E' suficiente lembrar as expressões que então usavam, quando se referiam ao poeta negro: Peregrino das Ânsias, Incomparável Eleito, Negro de Ouro, Glorioso Artista, Dor Personificada, Ser Privilegiado, Magoado Eleito, Semi-Deus, Tedioso e Torturado Sonhador, Grandioso e Imaculado Cenobita, Formidável Dan- 
te Negro. Cruz e Souza foi o "Deus tutelar da publicação" que acintosamente, exceção feita de Luís Delfino, desprezava os consagrados, chamados fósseis e desonestos. Por isto, se faltava matéria da autoria de simbolistas, preferiam transcrever Nietzche, Sar Peladan, Mallarmé, os poetas malditos (19).

Contando-se ainda o ressurgimento da Rosa-Cruz em 1904, com a sobrevivência do grupo de Saturnino Meireles que já havia falecido, temos então o fim do simbolismo no Brasil, considerado como movimento literário mais ou menos organizado e ativo. De 1904 em diante, o simbolismo continua a existir, mas apenas através de expressões individuais, algumas de grande valor, como Alphonsus de Guimaraens, Mário Pederneiras, poetas, e Nestor Victor, o crítico que foi o principal unificador daquela tendência literária entre nós.

Lembramos que, durante o desenvolvimento do simbolismo no Brasil, da última década do século XIX à primeira do seguinte, continuava a desenvolver-se a poesia parnasiana que era mais aceita e portanto mais vitoriosa que a poesia simbolista. Esta, nos últimos momentos, adquiriu, com alguns nomes a ela ligados, um caráter precursor do modernismo atual. E Nestor Victor foi talvez a principal expressão da crítica aproximadora dos novos que surgiram durante a segunda e a terceira décadas do século em curso e as manifestações simbolistas imediatamente anteriores.

A crítica histórica cita vários nomes de simbolistas, de pré-modernistas e de poetas de transição do parnasianismo para o simbolismo, nem sempre havendo coincidência entre as diversas opiniōes. Vejamos algumas. Ronald de Carvalho admite como pertencentes ao simbolismo os poetas Cruz e Souza, B. Lopes, Emílio de Menezes, Nestor Victor (ressaltado como crítico), Félix Pacheco, Alphonsus de Guimaraens, Silveira Neto, Mário Pederneiras, e os prosadores Cruz e Souza e Gonzaga Duque $(20)$.

Nelson Werneck Sodré indica Cruz e Souza, Alphonsus de Guimaraens, Nestor Victor (ressaltado como crítico), B. Lopes, Mário Pederneiras, Gonzaga Duque, Emílio de Menezes, Augusto dos Anjos, êste apontado como preso ao cientificismo introduzido no Brasil por intermédio de Portugal (21).

Agripino Grieco cita Cruz e Souza, Emiliano Perneta, Silveira Neto, Alphonsus de Guimaraens; coloca, conforme o título de um capítulo da obra que citamos (32), "Entre o parnasianismo e o simbolismo", os seguintes: Augusto dos Anjos, Raul de Leoni, Alceu Wamosy, Eduarao 
Guimaraens, Amaral Ornelas, Teodorico de Brito, Alberto Ramos, Pereira da Silva, Belmiro Braga, Olegário Mariano, Pinheiro Viegas, Onestaldo de Penaforte, Atílio Milano, Da Costa e Silva, Cleômenes Campos, Paulo Gonçalves, Oliveira e Silva, Angelina Macedo, Auta de Souza, Cecília Meireles, Lia Correia Dutra; e menciona como sonetistas exímios: Júlio Salusse, Ciro da Costa, Padre Antônio Tomaz, Raul Machado, Aníbal Teófilo.

Jaime de Barros menciona Cruz e Souza, Emiliano Perneta, Silveira Neto, Mário Pederneiras, Nestor Victor, Francisco Mangabeira, Alphonsus de Guimaraens, e Augusto dos Anjos que é posto entre o parnasianismo e o simbolismo; como pré-modernistas: Raul de Leoni, Hermes Fontes, Pereira da Silva, Da Costa e Silva e vários outros (23).

Finalmente, Edison Lins arrola como simbolistas os mesmos nomes apontados na obra de Ronald de Carvalho (24).

Achamos que as classificações acima são um tanto caprichosas, merecedoras de revisão. Não podem ser tomadas como definitivas; ao demais, o capítulo referente ao simbolismo em nossa história literária ainda não foi devidamente escrito e é certo que devemos tomar precaução contra qualquer esquematização precipitada. Não pretendemos nem podemos apresentar por enquanto uma classificação; apenas indico aqui os nomes dos que achamos verdadeiramente responsáveis pela existência do simbolismo no Brasil, e assim mesmo os nomes dos mais ressaltados: poetas: Cruz e Souza, Mário Pederneiras, Saturnino Meireles, Silveira Neto, Alphonsus de Guimaraens e, com algumas restrições, B. Lopes e Emiliano Perneta; prosadores: Cruz e Souza e Gonzaga Duque; crítico: Nestor Victor.

\section{N O T A S :}

1 - T. A. Araripe Junior - Movimento de 1893, Rio de Janeiro, Tip. da Emprêsa Democrática Editora, 1896. Págs. 66-112.

2 - Idem, op. cit., pág. 67.

3 - Idem, op. cit., pág. 68.

4 - Idem, op. cit., pág. 69-70.

5 - Idem, op. cit., pág. 70 (nota).

6 - Andrade Muricy - B. Lopes in Poesias completas de B. Lopes, 1.० vol., Rio de Janeiro, Liv. Editora Zélio Valverde, 1945. Págs. 19-20.

7 - Araripe Júnior, op. cit., pág. 90. 
8 - Eloy Pontes - A vida exuberante de Olavo Bilac, $2 .^{\circ}$ vol., Rio de Janeiro, Liv. José Olímpio Editora, 1944. Págs. 506 e 509.

9 - Carlos D. Fernandes - UM DOS PINTORES DISSIDENTES in Autores e livros - suplemento literário de $A$ Manhâ, a. II, vol. III, n.0 17, Rio de Janeiro, 6.12.1942. Págs. 263 e 266.

10 - Nestor Victor - $O$ suave convivio (livro de Andrade Muricy) in $O$ mundo literário, a. I, vol. 3, n.o VIII, Rio de Janeiro, 5.12.1922. Pág. $14 \bar{j}$.

11 - Carlos D. Fernandes, loc. cit..

12 - Lima Campos - GENTE DE UM TEMPO - TODDA UMA ÉPOCA - GONZAGa DUQUE - MÁRIO PEDERNEIRAS - "OS SIMBOLISTAS" in Autores e livros - suplemento literário de A Manhâ, vol. III, n.o 17, a. II, Rio de Janeiro, 6-12-1942.

13 - Gonzaga Duque - CARTAS INÉDITAS DE GONZAGA DUQUE in Terra de sol, vol. I, Rio de Janeiro, 1924. Págs. 29.

14 - Idem, ibidem, pág. 29.

15 - A. Austregésilo - REMINISCENCIA DO SIMBOLISMO in Autores $e$ livros - suplemento literário de $A$ Manhã, a. II, vol. III, n. 12, Rio de Janeiro, 18-10-1942. Pág. 186.

16 - C. Tavares Bastos - COMO SURGIRAM OS MítTICOS DA "ROSA-CRUZ" - O SIMBOLISMO NO BRASIL - A INFLUENCIA DE SATURNINO MEIRELES - OS DISCAPULOS DE CRUZ E SOUZA - VICISSITUDES DE UMA REVISTA DE ARTE in Jornal do Comércio, Rio de JaCo., New-York, 1942 - pág. 424; e Brazil, ed. Odyssey Press, New-York. neiro, 14-3-1947, pág. 7 .

17 - (Souza Bandeira) Félix Pacheco - Discurso de recepçâo na Academia, seguido da resposta do Sr. Souza Bandeira, Rio de Janeiro, Tip. do Jornal do Comércio, 1913. Págs. 69 et segs..

18 - Apud Tavares Bastos, loc. cit.

19 - Souza Bandeira, loc. cit..

20 - Ronald de Carvalho - Pequena história da literatura brasileira, c. pref. de Medeiros e Albuquerque, $2 .^{a}$ ed. rev. e aum., Rio de Janeiro, F. Briguiet \& Comp., editores, 1922. Págs. 352 et segs..

21 - Nelson Werneck Sodré - História da literatura brasileira, 2.8 ed. rev. e aum., Rio de Janeiro, Liv. José Olimpio Editôra, 1940. Págs. 201 et segs. .

22 - Agripino Grieco - Evolução da poesia brasileira, 2.a ed., Rio de Janeiro, Liv. H. Antunes, 1944. Págs. 106-121, 122 et seqs..

23 - Jaime de Barros - Poetas do Brasil, Rio de Janeiro, Liv. José Olimpio Editora, 1944. Págs. 111-119, 121 et segs..

24 - Edison Lins - História e crítica da poesia brasileira, Rio de Janeiro, Ariel, 1937. Págs. 189 et seqs.. 